\title{
Assessing the utility of leukocyte differential cell counts for predicting morbidity, mortality, and growth in a grain-fed veal facility: A prospective single cohort study
}

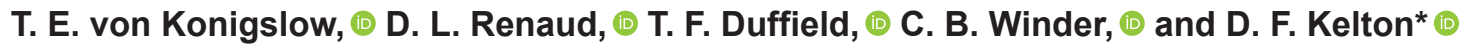 \\ Department of Population Medicine, University of Guelph, Guelph, ON, Canada N1G 2W1
}

\begin{abstract}
Selective antimicrobial treatment strategies present a means to reduce antimicrobial use at the time of arrival at a veal or dairy beef operation. On-farm machine leukocyte differential cell counts (DCC) that can be acquired quickly may be useful to augment calf risk identification protocols. The objective of this study was to assess the utility of DCC taken at the time of arrival at a grain-fed veal facility and $72 \mathrm{~h}$ postarrival for determining morbidity risk, mortality risk, and growth during the production cycle. Data were collected between June and October 2018 from 240 calves upon arrival and from a subset of 160 calves $72 \mathrm{~h}$ postarrival at a commercial grain-fed veal facility in Ontario, Canada. Blood samples were evaluated using the QScout BLD test for leukocyte DCC (Advanced Animal Diagnostic, Morrisville, NC). All calves were screened using a standardized health examination, and a blood sample was collected to evaluate serum total protein and DCC. Cox proportional hazards models were constructed for both morbidity and mortality outcomes. Mixed linear regression models were constructed to evaluate average daily gain. Results from data collected at the time of arrival suggest that total protein values $\geq 5.2 \mathrm{~g} / \mathrm{dL}$ reduced the hazard of mortality and that a rectal temperature $>39.6^{\circ} \mathrm{C}$ was associated with an increased hazard of morbidity. Calves that were dehydrated gained less, whereas calves with an increased lymphocyte count had a higher rate of growth. Results from DCC collected $72 \mathrm{~h}$ postarrival suggest that lymphocyte counts between 4.8 and $5.8 \times 10^{9}$ cells/L decreased the hazard of mortality and counts $>7.0 \times 10^{9}$ cells $/ \mathrm{L}$ decreased the hazard of morbidity, whereas neutrophil counts $>6.0 \times 10^{9}$ cells/L increased the hazard of mortality. This study demonstrates that machine DCC at the time of arrival and $72 \mathrm{~h}$ after arrival has potential for use in identifying high-risk calves that might require
\end{abstract}

Received March 14, 2020.

Accepted May 29, 2020.

*Corresponding author: dkelton@uoguelph.ca treatment, as part of selective antimicrobial therapy protocols, with the purpose of reducing antimicrobial use without sacrificing animal health in veal facilities. Key words: calf, health indicator, risk assessment

\section{INTRODUCTION}

Group metaphylaxis at the time of arrival is common in the veal and dairy beef industries in response to the high levels of morbidity and mortality observed in the first $21 \mathrm{~d}$ after arrival at calf rearing facilities (Renaud et al., 2018a; Santman-Berends et al., 2018; Scott et al., 2019). This high morbidity and mortality could be a consequence of the young age of calves that undergo stressful events before arrival, such as comingling, transportation, and variable periods of fasting before their immune and physiological systems are capable of coping with such challenges (Marcato et al., 2018). Despite the occurrence of these challenges, growing interest in reducing antimicrobial use in food-producing animals is leading to widespread changes in the use of antimicrobials in animal agriculture (Speksnijder and Wagenaar, 2018). Group prophylaxis and metaphylaxis have been banned or restricted in some countries that are members of the European Union (EMA Committee for Medicinal Products for Veterinary Use et al., 2017), and similar restrictions may be implemented in North America in the future.

A selective antimicrobial therapy strategy at the time of arrival targeting the calves at highest risk of morbidity and mortality early in the production cycle could present a viable alternative to group therapy and reduce antimicrobial use (Renaud et al., 2018 a,d). However, these strategies need to ensure the preservation of calf health and welfare and protect the economic viability of this industry (Marcato et al., 2018; von Konigslow et al., 2019). It is common for calves to arrive at veal facilities without information about their age or history of early life management, particularly if they are sourced from multiple locations or auction barns. With little or no other information available, there is a need for methods to identify calves at high 
risk for morbidity and mortality based on what can be observed or measured at the time of arrival.

Recent studies have identified indicators of future risk of morbidity, mortality, and reduced growth, such as biomarkers and clinical exam findings in veal or dairy beef calves at the time of arrival at the facility (Winder et al., 2016; Renaud et al., 2018b,d). Leukocyte counts have the potential for use as biomarkers of health and performance when interpreted in conjunction with clinical exam findings in cattle of all ages (Mohri et al., 2007; Roland et al., 2014; Marcato et al., 2018). More specifically, leukocyte counts, leukograms, and sequential leukograms can be used for health assessments, disease diagnostics, monitoring, and to establish prognosis (Roland et al., 2014). An important practical consideration for decision making on farm is that measurements should be reasonably fast to obtain, be minimally invasive to the calf, and return a quick result. If leukocyte differential cell counts (DCC) prove to be a good indicator of future health and growth, rapid onfarm machine leukocyte differential cells counters, such as the QScout BLD (Advanced Animal Diagnostics, Morrisville, NC), may aid in informing decision making on arrival (von Konigslow et al., 2019).

The objective of this prospective cohort study was to assess the utility of leukocyte DCC measured at the time of arrival for determining morbidity risk, mortality risk, and ADG in grain-fed veal calves. A secondary objective was to evaluate leukocyte DCC in a subset of calves taken $72 \mathrm{~h}$ postarrival to determine whether the values differed from the initial measurement and whether there was any improvement in utility for determining future risk of morbidity, mortality, and ADG. It was hypothesized that (1) leukocytes can be used as an indicator of future health and growth in veal calves after transportation and (2) leukocyte DCC will differ between sampling time points and samples taken $72 \mathrm{~h}$ postarrival may exhibit improved ability for determining future health and growth. This paper is reported following the Strengthening the Reporting of Observational Studies in Epidemiology-Veterinary Extension guidelines (Sargeant et al., 2016).

\section{MATERIALS AND METHODS}

\section{Study Design}

Calves were enrolled in this study at a single grainfed veal facility in Ontario, Canada. The facility was selected based on convenience. The calves were originally enrolled for a diagnostic accuracy study (von Konigslow et al., 2019) and a nonantibiotic feed additive trial where no differences were found between treatment groups (D. L. Renaud, unpublished data). The nonantibiotic feed additive trial measured the following outcomes: mortality, antibiotic use, respiratory health (McGuirk and Peek, 2014), and fecal consistency (McGuirk, 2008). This study adhered to the Animal Care Committee requirements of the University of Guelph (Animal Use Protocol no. 3850). Data were collected between June 11, 2018, and October 9, 2018.

\section{Animal Enrollment}

All calves that arrived at the veal facility between June 11 and July 26, 2018, were eligible for enrollment. Calves were Holstein males of unknown age sourced from local dairy farms or auction barns. Calf age was estimated to be between 3 and $7 \mathrm{~d}$ based on a recent study of male calf management on dairy farms (Renaud et al., 2018c). Each room was filled over a period of 1 to $2 \mathrm{~d}$, and calves were housed in individual slatted floor pens $(78 \mathrm{~cm} \times 128 \mathrm{~cm})$ for the milk feeding period and at weaning were placed into groups of 5 adjacent calves. The facility comprised 4 rooms, each with the capacity to house 80 calves. A total of 240 calves in 3 rooms $(80$ calves per room) were enrolled and followed for $77 \mathrm{~d}$ until they were shipped to another location for finishing. Calves were fed a $26 \%$ protein and $17 \%$ fat milk replacer (Mapleview Agri Ltd., Mapleton, ON, Canada) using the following schedule: $260 \mathrm{~g}$ in $2 \mathrm{~L}$ twice daily for wk 1 and 2; $325 \mathrm{~g}$ in $2.5 \mathrm{~L}$ twice daily for wk $3 ; 450$ $\mathrm{g}$ in $3 \mathrm{~L}$ twice daily for wk 4 and 5; $450 \mathrm{~g}$ in $3 \mathrm{~L}$ once daily for wk 6; $450 \mathrm{~g}$ in $3 \mathrm{~L}$ every third feeding for wk 7; and completely weaned for wk 8. Calves had free access to water and grain for the entire period. Grain offered was a textured calf starter $(18 \%$ CP; Wallenstein Feed \& Supply Ltd., Wallenstein, ON, Canada) upon arrival until wk 3 and transitioned to corn and pellet ration with $2 \%$ straw (18.1\% CP; Wallenstein Feed \& Supply Ltd.) for the remainder of the experimental period.

\section{Data and Sample Collection}

Health Measurements. Immediately upon arrival, each calf was evaluated using a standardized health scoring system. Calves were evaluated before having access to water on farm. A health score for each individual calf was assigned by 1 of 2 observers, one a practicing large-animal veterinarian and the other a trained research assistant. The health scores represent a subset of risk factors associated with mortality in veal calves (e.g., barn, season, source, navel score, cough score, hydration score, sunken flank, and arrival weight; adapted from Renaud et al., 2018a). The "other" score allowed detectable health abnormalities not listed in the original protocol to be captured, such as an infected wound or heavy ocular discharge (equivalent to score 3 on the 
respiratory scoring system developed by McGuirk and Peek, 2014). Laminated reference sheets with health score images and definitions were available at all times during scoring and are available as Supplemental Figure S1 (https://doi.org/10.3168/jds.2020-18532). Rectal temperature was measured using a digital thermometer (MC-343F-E, Omron Healthcare, Burlington, ON, Canada). A metal dowel (20 mm diameter) was used as a reference for assessing navel diameter scores. Navel size was also measured using a digital caliper (150-mm digital vernier caliper, MasterCraft Brand Tools, Toronto, ON, Canada). An iPad (Apple Inc., Cupertino, CA) was used to record all health data using Qualtrics (https://www.qualtrics.com/). Inter- and intraobserver evaluation of health scores were performed on 10 calves to ensure agreement between and within observers.

Blood Measurements. Two blood samples were obtained from each calf at the time of arrival by jugular venipuncture. These blood samples were chilled within minutes of collection in a cooler with ice packs. One blood sample was taken using a $10-\mathrm{mL}$ serum vacuum tube and 18-gauge, 1-inch Vacutainer needle on a plastic hub (BD Vacutainer serum blood collection tubes, Franklin Lakes, NJ). This blood sample was centrifuged at $2,188 \times g$ for $10 \mathrm{~min}$ within $5 \mathrm{~h}$ of collection and then stored in a refrigerator at $4^{\circ} \mathrm{C}$ for analysis within $12 \mathrm{~h}$ of collection. Stored serum samples were transferred to an optical refractometer (RHC-200ATC, SinoTech, Fujian, China) using a new disposable pipette for each sample. Values were visually determined, and results were first recorded on paper and then entered into a Microsoft Excel spreadsheet (v. 16.32, Microsoft Corp., Redmond, WA). The research assistant performed serum total protein analysis and was blinded to the health scores, measurements, and machine white blood cell differential results. A 20- $\mu$ L EDTA blood collection device (QDraw v. ASM9033-C, Advanced Animal Diagnostics) was used to collect the second blood sample. Blood leukocyte counts can be affected by the stress of prolonged transportation, with the reported effect varying from $1 \mathrm{~d}$ to several days (Odore et al., 2004; Bernardini et al., 2012; Yun et al., 2014). To allow calves time to adjust to their new diet and environment posttransportation, an arbitrarily selected time of $72 \mathrm{~h}$ after arrival was used to obtain a third 20- $\mu$ L EDTA blood sample from a convenience subset of 160 calves representing the second and third rooms enrolled. The samples collected in EDTA were analyzed within minutes of collection using a white blood cell differential machine (QScout BLD, Advanced Animal Diagnostics). The leukocyte differential machine used (QScout Cattle Lab, software v. 1.0.6.20023, Advanced Animal Diagnostics) was recently validated for use in neonatal Holstein calves (von Konigslow et al., 2019). Blood samples from each calf were loaded into the well of a test slide cartridge (QScout BLD cartridge version ASM9041-C, Advanced Animal Diagnostics). The slide cartridge was examined by automated microscopy and analyzed using the proprietary software (QScout Cattle Lab, software v. 1.0.6.20023). Results were obtained within 1 min of loading the sample (Kull et al., 2018).

Growth Measurements. Calves were weighed using a digital weigh scale (Tru-Test, Mineral Wells, TX) by farm staff before being moved into individual pens at the time of arrival. Calves were fed at the veal facility until d 77, when final individual calf weights were also obtained. The ADG was calculated for each calf by dividing the amount of weight gained (final weight - arrival weight) by the number of days on feed at the facility $(77 \mathrm{~d})$.

Treatment and Mortality Records. Group metaphylaxis was not provided at the time of arrival in accordance with routine farm protocol. Individual animal health assessment and treatments were administered by farm staff twice daily according to facility protocols. Facility protocols for individual animal health assessment and treatment were developed with veterinary oversight and based on fecal and respiratory scoring systems (McGuirk, 2008; McGuirk and Peek, 2014). Fecal scoring was performed immediately before milk feeding, and respiratory scoring was performed shortly after milk feeding. Assessments and treatments were performed by experienced facility personnel. Treatment and mortality records were provided in a Microsoft Excel spreadsheet (v. 16.32, Microsoft Corp.) to researchers after calves were shipped from the facility.

\section{Sample Size Calculation}

This study was conducted concurrently with a diagnostic accuracy study to validate the leukocyte differential count machine (von Konigslow et al., 2019). Sample size determination was conducted for the validation study, and then calves were followed for the remainder of the $77-d$ production cycle. The blood sample data were assumed to have normal distribution and to be within $10 \%$ of the true upper and lower population intervals. The method for sample size determination described by Hahn and Meeker (2011) for tolerance intervals was used assuming $95 \%$ confidence in capturing $95 \%$ of the population (Hahn and Meeker, 2011). This resulted in an estimated sample size of 173 calves. A total of 240 calves in 3 rooms ( 80 calves per room) were enrolled in this study to account for potential missing data and to enroll all calves arriving within a room. 


\section{Analysis}

Statistical analyses were performed using Stata 15 (StataCorp LP, College Station, TX). Data were imported to Stata 15 from a Microsoft Excel spreadsheet (v. 16.32, Microsoft Corp.). Calves that had missing outcome data (morbidity, mortality, or ADG), health scores, leukocyte DCC on arrival, or leukocyte DCC $72 \mathrm{~h}$ postarrival were excluded from further analysis. Although Cohen's kappa can be used to calculate interand intraobserver evaluations even for small samples sizes $(\mathrm{n}=5)$, this can lead to a relatively large standard error resulting in low precision; thus, inter- and intraobserver evaluations were performed using percent agreement (McHugh, 2012).

Descriptive statistics were generated for health measurements on the day of arrival as well as white blood cell differential counts measured on the day of arrival and $72 \mathrm{~h}$ postarrival. The Shapiro-Wilk test for normality was applied to the leukocyte DCC variables. A Wilcoxon matched-pairs sign-rank test (nonparametric) or a paired $t$-test (parametric) was performed based on the Shapiro-Wilk test results to establish whether leukocyte cell counts were significantly different between measurement at the time of arrival and 72 $\mathrm{h}$ postarrival.

Figure 1 illustrates the hypothesized causal diagram between outcome and explanatory variables that was used to guide model building. The causal diagram was built by hypothesizing the relationship between health measurements that are measurable at the time of arrival and future health and growth. In the causal diagram, explanatory variables were placed on the left in their hypothesized causal order and tracing a path, using arrows, toward the outcomes of interest on the right. From the white blood cell differential counts generated by the QScout BLD test, eosinophils and monocytes were excluded from model building because they were found to have only slight agreement with the current gold standard test in this population of animals (von Konigslow et al., 2019). From the health measurements assessed, the "other score" health abnormality was excluded as very few abnormalities were recorded (Table 1). As few animals had a dehydration score above 1 , this was collapsed to a binary variable (dehydrated, not dehydrated). A Spearman's rank coefficient was used to assess collinearity among explanatory variables, with coefficients $>0.6$ being further scrutinized. For collinear variables, the most biologically relevant or reliable measure was retained in the model. Navel size and navel score were found to be correlated. Navel score was retained in the model as recent studies have determined this measure to be an indicator of early mortality risk (Renaud et al., 2018a,b). Neutrophil:lymphocyte ra- tio was correlated with neutrophil counts. Neutrophil counts were retained in the model as they were found to have better agreement with the current gold standard in this population of calves (von Konigslow et al., 2019). Total leukocyte count was correlated with both neutrophil and lymphocyte counts. Neutrophil and lymphocyte counts were retained in the model as these measures were recently validated in this population of animals and they make up a large proportion of the total leukocyte counts (von Konigslow et al., 2019). For all outcomes of interest, linearity was assessed using locally weighted regression (lowess) of the outcome on the explanatory variable. Variables that failed to meet the linearity assumption were categorized. The serum total protein variable was measured in increments of 0.1 $\mathrm{g} / \mathrm{dL}$ and was categorized using a biological cut point of $5.2 \mathrm{~g} / \mathrm{dL}$, resulting in 2 categories $(<5.2$ and $\geq 5.2 \mathrm{~g} /$ dL; Buczinski et al., 2018). Other variables that failed to meet the linearity assumption were categorized into quartiles (arrival weight, rectal temperature, neutrophil counts, lymphocyte counts).

Cox proportional hazard models were constructed to assess the relationship between the time to morbidity or mortality event (in the first $21 \mathrm{~d}$ on feed and over the entire 77-d study period) and the explanatory variables at 2 time points (time of arrival and $72 \mathrm{~h}$ postarrival). Mixed linear regression models were constructed to assess the relationship between the 2 explanatory variable measurement time points (time of arrival and $72 \mathrm{~h}$ postarrival) and the ADG over the 77-d study period. The health measurement explanatory variables included blood leukocyte DCC (measured at 2 time points), health scores, weight, rectal temperature, and serum total protein. All models included a random effect to account for clustering by room. Univariable models for all explanatory variables were screened using a $P$-value of 0.2. Models were constructed using manual backward stepwise selection. Statistical significance was defined as $P \leq 0.05$. Biologically plausible 2 -way interactions were explored (Figure 1). Variables were retained in the model if they were part of a 2-way interaction with an explanatory variable that met the criteria for being retained in the model. A variable was found to have a confounding effect and was retained in the model if its removal changed the coefficient of a variable that met the criteria for being retained in the model by more than $20 \%$. Model assumptions and model fit were evaluated in all models. Influential observations were investigated to ensure that data records were complete and biologically plausible. Cox proportional hazards models were evaluated by examining deviance, Martingale residuals, Cox-Snell residuals, and Schoenfeld residuals as well as the test for proportional hazards. Mixed linear regression models were evaluated by assessing normality and 


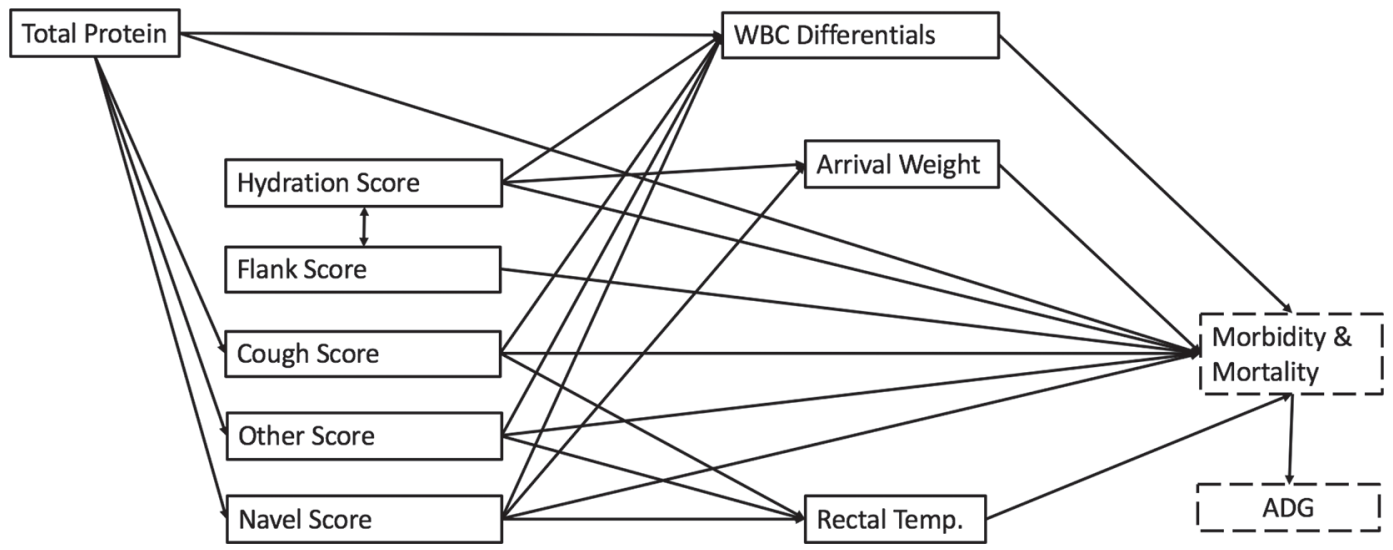

Figure 1. Causal diagram used to illustrate the hypothesized relationship between measured variables and the outcomes of interest morbidity, mortality, and ADG. $\mathrm{WBC}=$ white blood cell; Temp. = temperature.

homoscedasticity of residuals as well as the BLUP for random effects.

\section{RESULTS}

\section{Animal Population}

A total of 240 calves arrived at the grain-fed veal facility between June 11 and July 26, 2018, and were enrolled in the study (arrival data set). All calves were Holstein males of unknown age and history. The estimated age of the calves enrolled was between 3 and $7 \mathrm{~d}$ of age at the time of arrival based on calf arrival weight and recent findings that less than one-fifth of source dairy farms keep male dairy calves beyond $7 \mathrm{~d}$ (Renaud et al., 2018c). A convenience subset of 160 animals from the enrolled calves was revisited for blood collection 72 $\mathrm{h}$ after arrival (subset data). Figure 2 presents a flowchart of the number of calves enrolled and the reason for exclusion from analysis for each outcome in this study. Of the 240 calves that were enrolled, outcome data were missing for 10 calves (missing health measure scores, $\mathrm{n}=5$; missing blood test results, $\mathrm{n}=5$ ). From the 160 calves in the subset revisited $72 \mathrm{~h}$ later, 10 calves had missing outcome data (missing initial health score, $\mathrm{n}=4$; missing initial blood test, $\mathrm{n}=5$ ) or had

Table 1. Distribution of health measurement scores evaluated on the day of arrival from 230 calves at a grain-fed veal facility in southwestern Ontario, and distribution of health measurement scores on the day of arrival for the subset of 150 calves revisited for blood collection $72 \mathrm{~h}$ postarrival

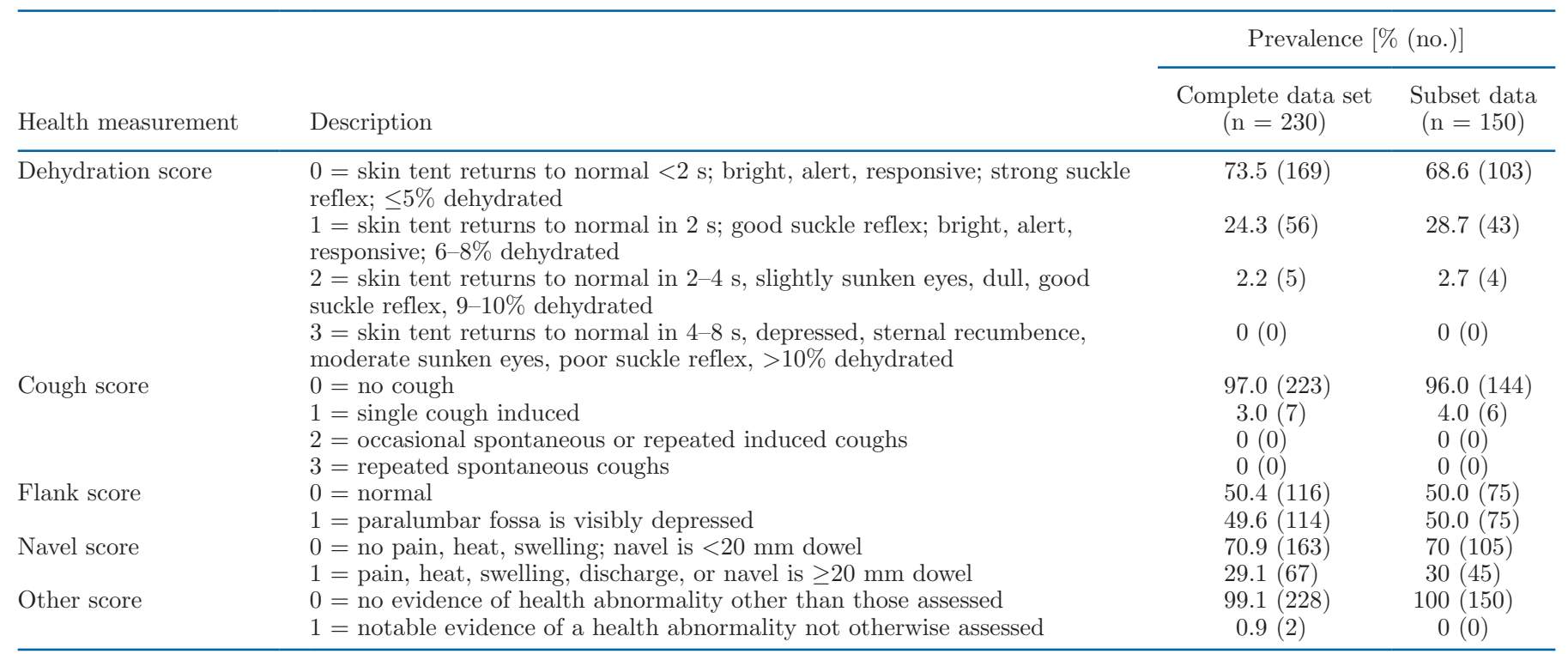




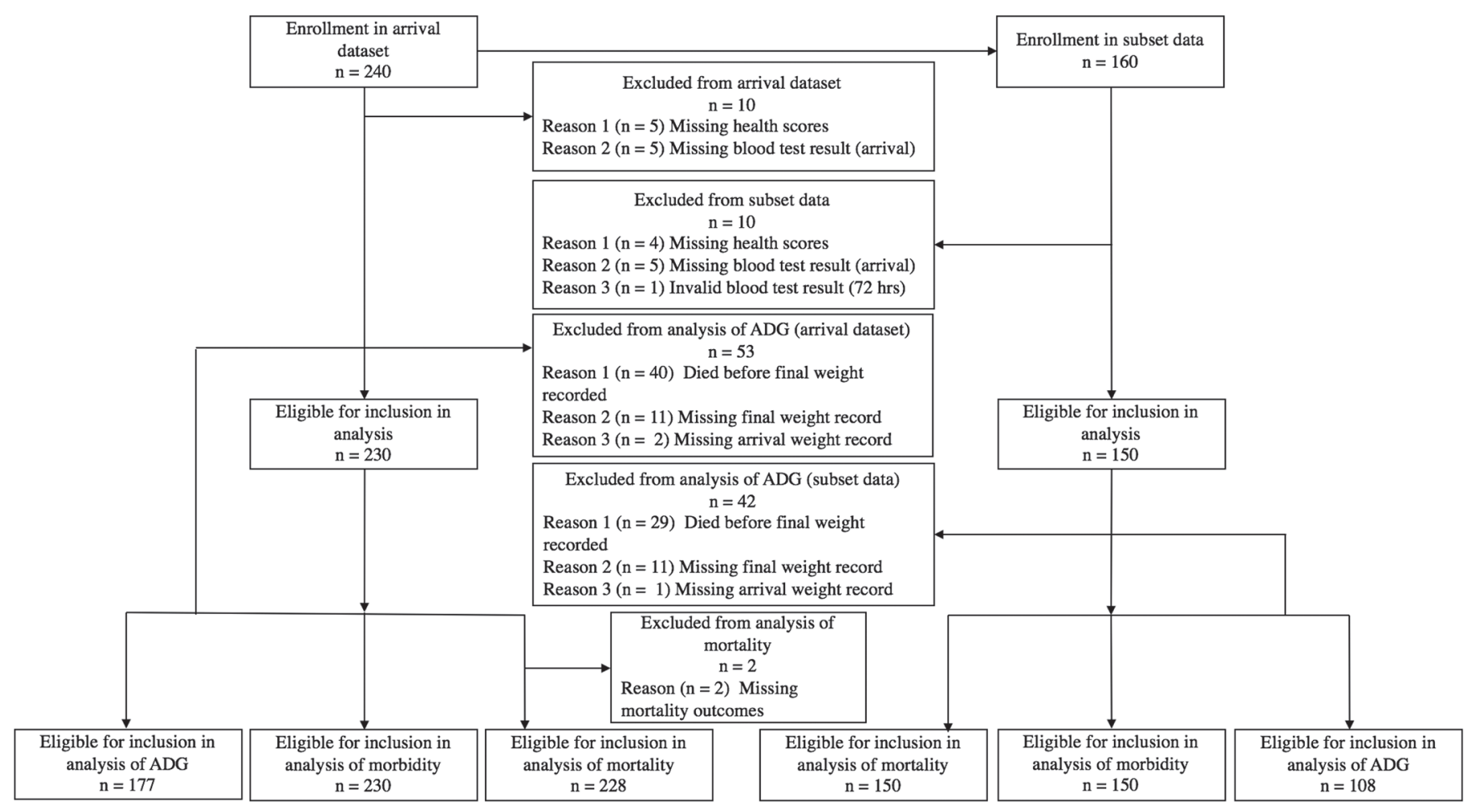

Figure 2. Diagram illustrating subject flow through the study, with reasons for missing data by outcome.

a leukocyte differential test that did not return a valid result $(\mathrm{n}=1)$.

\section{Health Measurements}

Table 1 describes calf health scores within the arrival data set and subset data. More than one-quarter (26.5\%) of the calves arrived with some level of dehydration. Half of the calves $(49.6 \%)$ had a sunken paralumbar fossa, which could be indicative of a prolonged period since their last feeding. Approximately 30\% of calves arrived with an abnormal navel score, and less than 5\% of calves arrived with a detectable health abnormality, such as a cough or other detectable abnormality. Mean rectal temperature was $39.4^{\circ} \mathrm{C}\left(\mathrm{SD}: 0.42^{\circ} \mathrm{C}\right.$ ), with $27 \%$ of calves having a rectal temperature $>39.5^{\circ} \mathrm{C}$. Mean navel size was $18.20 \mathrm{~mm}$ (SD: $7.57 \mathrm{~mm}$ ).

\section{Inter- and Intraobserver Agreement}

Agreement between observers was 95\% for navel score evaluation, $75 \%$ for hydration score evaluation, $90 \%$ for sunken flank evaluation, and 100\% for cough score and "other" score evaluation. Intraobserver percent agreement was 100\% for all health measurements except sunken flank, which was $90 \%$ for both observers.

\section{Blood Measurements}

Table 2 describes blood measurement results for both the complete data set and subset. Only a small percentage of each blood measurement assessed on the day of arrival was outside of reported reference intervals for neonatal Holstein calves (Panousis et al., 2018). Using the Shapiro-Wilk test for normality, lymphocyte count data were determined to be the only blood measurement normally distributed $(P=0.74)$. Before analyzing the subset data taken $72 \mathrm{~h}$ postarrival, tests were performed to confirm that leukocyte count data were statistically different between test dates. Lymphocyte test values were different between test days $(P<0.01)$, with $3.5 \%$ measuring equally above or below the reported reference interval at the time of arrival. At 72 $\mathrm{h}$ postarrival, $7.4 \%$ of the lymphocyte counts measured outside of the reference interval; all but 1 measurement were above the upper limit. Neutrophil counts were different between test days $(P<0.01)$, with $2.6 \%$ measuring equally above or below the reference interval at the time of arrival and $1.7 \%$ measuring either above or below the reference interval $72 \mathrm{~h}$ postarrival. Monocyte counts were also different between test days $(P<0.01)$, with $0.9 \%$ measuring below the lower reference interval at the time of arrival and $0.4 \%$ measuring above the 
upper reference interval $72 \mathrm{~h}$ postarrival. Neutrophil: lymphocyte ratio was also different between test days $(P<0.01)$, with $0.4 \%$ measuring below the lower reference interval at the time of arrival and $0.9 \%$ measuring below the lower reference interval $72 \mathrm{~h}$ postarrival. Total leukocyte count $(P=0.88)$ and eosinophil counts $(P=$ $0.31)$ were not different between test dates. The mean serum total protein for calves at the time of arrival was $5.5 \mathrm{~g} / \mathrm{dL}$ (SD: $0.05 \mathrm{~g} / \mathrm{dL}$ ), with $30 \%$ experiencing failure of passive transfer of immunity using a cut point of $5.2 \mathrm{mg} / \mathrm{dL}$ (Calloway et al., 2002; Godden, 2008; Renaud et al., 2018a).

\section{Mortality Models}

Over the 77 -d study period, $16.7 \%$ mortality was observed, with $7.0 \%$ dying within the first $21 \mathrm{~d}$ on feed. Figure 3A illustrates the time to mortality in all calves over the 77-d study period. Records included cause of death as reported by farm staff. All deaths reported in the first $21 \mathrm{~d}(\mathrm{n}=16)$ after arrival were reported as diarrhea and dehydration. All but 1 of the deaths reported after $21 \mathrm{~d}(\mathrm{n}=22)$ were recorded as pneumonia. One calf was reported to have died from diarrhea and dehydration after $21 \mathrm{~d}$.

Two calves were excluded from the hazard models of mortality because of missing farm records for mortality (Figure 2). There were not sufficient mortality outcomes within the first $21 \mathrm{~d}$ on feed to assess hazard models in this time frame. For the 77-d study period, the serum total protein explanatory variable measured at the time of arrival was associated with the hazard of mortality. Serum total protein values $\geq 5.2 \mathrm{~g} / \mathrm{dL}$ were found to reduce the hazard of mortality by $71 \%$ (hazard ratio, $\mathbf{H R}=0.29 ; 95 \% \mathrm{CI}=0.15-0.55 ; P<$ 0.01) compared with calves with a serum total protein $<5.2 \mathrm{~g} / \mathrm{dL}$. The importance of the blood leukocyte count explanatory variables measured $72 \mathrm{~h}$ postarrival for predicting the hazard of mortality is summarized in Table 3. Lymphocyte counts falling between 4.6 and $5.8 \times 10^{9} / \mathrm{L}$ reduced the hazard of mortality by $78 \%$ $(\mathrm{HR}=0.22,95 \% \mathrm{CI}=0.05-0.87, P=0.03)$, whereas neutrophil counts $>6.0 \times 10^{9} / \mathrm{L}$ increased the hazard of mortality by more than 5 times $(\mathrm{HR}=5.21,95 \% \mathrm{CI}=$ $1.29-21.08, P=0.02)$.

\section{Morbidity Models}

Time to first treatment with antibiotics was used as a proxy for onset of morbidity. Over the 77-d study period, $96.5 \%$ of calves received at least 1 antibiotic treatment; $90.0 \%$ of them received a treatment within the first $21 \mathrm{~d}$ on feed, and $34.4 \%$ received a treatment within the first $3 \mathrm{~d}$ on feed. Of the calves that were

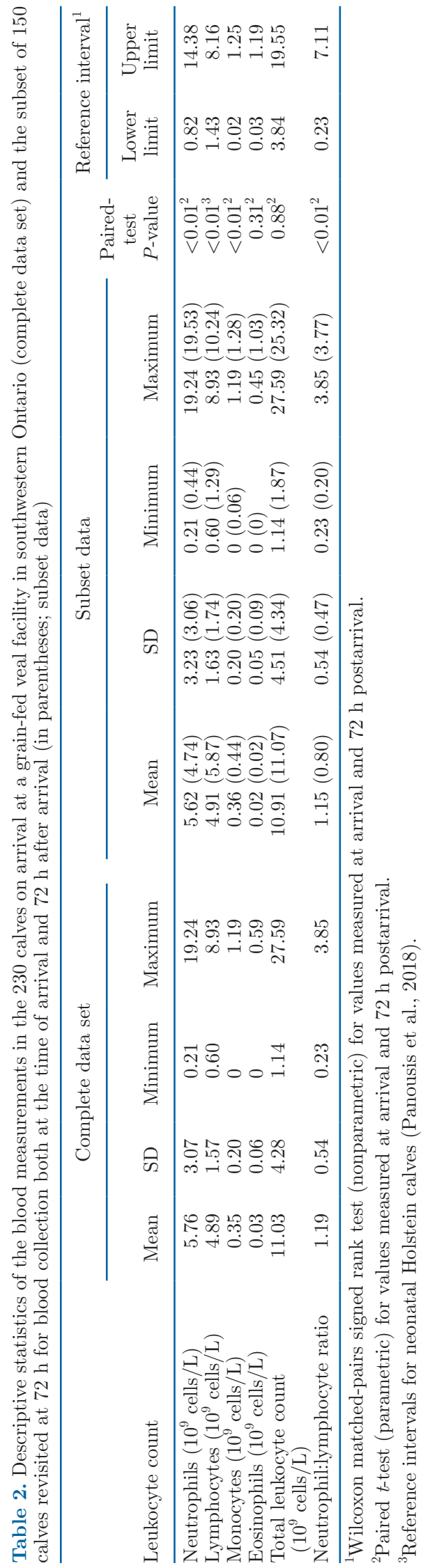


Table 3. Results of the Cox proportional hazard model assessing the significance of the explanatory variables measured from 150 calves $72 \mathrm{~h}$ postarrival for predicting the hazard of mortality over the entire 77 -d study period $^{1}$

\begin{tabular}{lccccc}
\hline Variable & $\begin{array}{c}\text { Calves } \\
\text { (no. })\end{array}$ & $\begin{array}{c}\text { Mortality } \\
\text { (no. of calves })\end{array}$ & $\begin{array}{c}\text { Hazard } \\
\text { ratio }\end{array}$ & $95 \%$ CI & $P$-value \\
\hline $\begin{array}{l}\text { Lymphocyte count }\left(10^{9} \text { cells } / \mathrm{L}\right) \\
\leq 4.6\end{array}$ & 37 & 9 & Referent & & \\
$>4.6-5.8$ & 37 & 3 & 0.22 & $0.05-0.87$ & 0.03 \\
$>5.8-7.0$ & 39 & 7 & 0.45 & $0.14-1.53$ & 0.20 \\
$>7.0$ & 37 & 10 & 0.51 & $0.14-1.89$ & 0.31 \\
Neutrophil count $\left(10^{9}\right.$ cells/L) & 37 & 4 & Referent & & \\
$\leq 2.7$ & 37 & 7 & 1.71 & $0.50-5.87$ & 0.40 \\
$>2.7-3.9$ & 39 & 4 & 1.35 & $0.30-6.01$ & 0.69 \\
$>3.9-6.0$ & 37 & 14 & 5.21 & $1.29-21.08$ & 0.02 \\
$>6.0$ & & & & & \\
\hline
\end{tabular}

${ }^{1}$ Random effect for clustering by the room in which calves were managed, $P=0.10$.

treated, $71 \%$ received more than 1 treatment. Figure 3B illustrates time to first treatment in all calves over the 77-d study period. Treatments were for diarrhea (69.6\%), pneumonia (23.0\%), and both pneumonia and diarrhea (3.5\%). Only $3.5 \%$ of calves were untreated over the study period.

Importance of the explanatory variables measured at the time of arrival for predicting the hazard of morbidity over the entire 77 -d study period is summarized in Table 4. Rectal temperature $>39.6^{\circ} \mathrm{C}$ was found to increase the hazard of morbidity by $48 \%$ ( $\mathrm{HR}=1.48$, $95 \% \mathrm{CI}=1.01-2.17, P=0.04)$. Room was statistically significant in the model $(P=0.02)$. Lymphocyte DCC, arrival weight, and navel scores were retained in the model as confounders.

The effect of the explanatory variables measured at the time of arrival for predicting the hazard of morbidity over the first $21 \mathrm{~d}$ of the study period is summarized in Table 5. Lymphocyte counts $>5.8 \times 10^{9} / \mathrm{L}$ reduced the hazard of morbidity by $41 \%(\mathrm{HR}=0.59,95 \% \mathrm{CI}$ $=0.37-0.95, P=0.03$ ), whereas rectal temperatures $>39.6^{\circ} \mathrm{C}$ increased the hazard of morbidity by more than 1.5 times $(\mathrm{HR}=1.54,95 \% \mathrm{CI}=1.04-2.27, P=$ $0.03)$. Room was statistically significant in the model $(P=0.04)$. Arrival weight, neutrophil DCC, and navel scores were retained in the model as confounders.

Findings for the blood leukocyte differential counts measured $72 \mathrm{~h}$ postarrival for predicting the hazard of morbidity over the entire 77 -d study period are summarized in Table 6. Lymphocyte counts $>7.0 \times 10^{9} / \mathrm{L}$ reduced the hazard of morbidity by $54 \%(\mathrm{HR}=0.56$, $95 \%$ CI $=0.35-0.90, P=0.02)$. The effect of blood leukocyte differential counts measured $72 \mathrm{~h}$ postarrival for predicting the hazard of morbidity over the first $21 \mathrm{~d}$ of the study period is summarized in Table 7 . Lymphocyte counts $>7.0 \times 10^{9} / \mathrm{L}$ reduced the hazard of morbidity by $63 \%$ ( $\mathrm{HR}=0.47,95 \% \mathrm{CI}=0.29-0.78$, $P<0.01)$.

\section{ADG Models}

Average daily gain was calculated by subtracting arrival weight from final weight and dividing by the $77-\mathrm{d}$ study period. Calves did not have an ADG outcome if
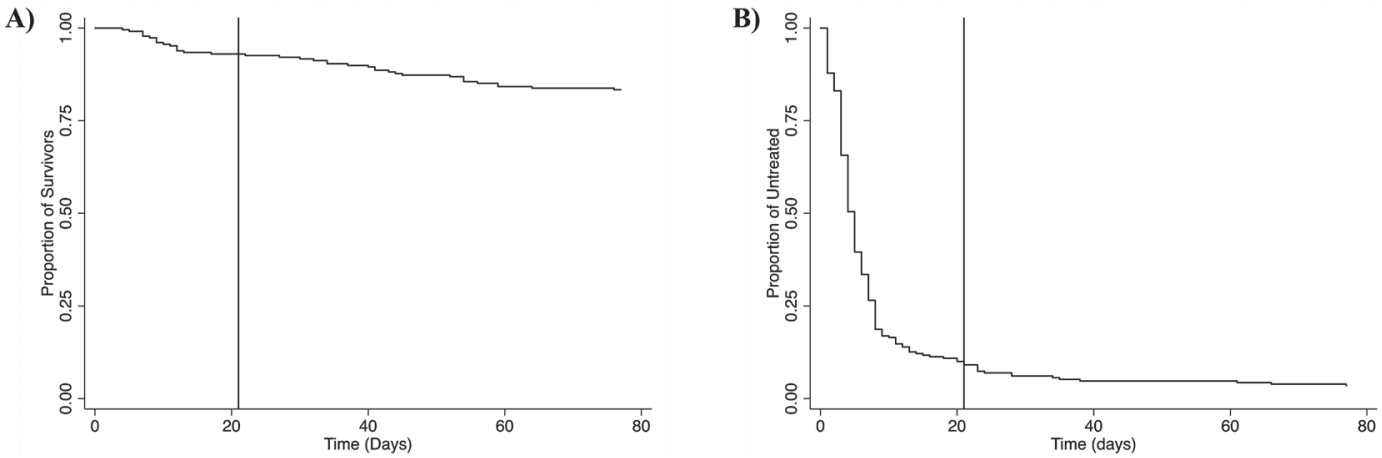

Figure 3. (A) Kaplan-Meier survivor curve of the proportion of calves that have survived over time $(\mathrm{n}=228)$. The vertical line marks the third week postarrival. (B) Kaplan-Meier curve of the proportion of calves remaining untreated with antimicrobials over time $(\mathrm{n}=230)$. The vertical line marks the third week postarrival. 
Table 4. Results of the Cox proportional hazard model assessing the significance of the explanatory variables measured from 230 calves at the time of arrival for predicting the hazard of morbidity over the entire 77-d study period ${ }^{1}$

\begin{tabular}{|c|c|c|c|c|c|}
\hline Variable & $\begin{array}{c}\text { Calves } \\
\text { (no.) }\end{array}$ & $\begin{array}{c}\text { Morbidity } \\
\text { (no. of calves) }\end{array}$ & $\begin{array}{l}\text { Hazard } \\
\text { ratio }\end{array}$ & $95 \% \mathrm{CI}$ & $P$-value \\
\hline \multicolumn{6}{|c|}{ Rectal temperature $\left({ }^{\circ} \mathrm{C}\right)$} \\
\hline$\leq 39.1$ & 72 & 69 & Referent & & \\
\hline$>39.1-39.3$ & 47 & 45 & 1.25 & $0.83-1.87$ & 0.29 \\
\hline$>39.3-39.6$ & 60 & 58 & 0.95 & $0.67-1.36$ & 0.79 \\
\hline$>39.6$ & 51 & 50 & 1.48 & $1.01-2.17$ & 0.04 \\
\hline \multicolumn{6}{|c|}{ Arrival weight $(\mathrm{kg})$} \\
\hline$\leq 44.5$ & 51 & 50 & Referent & & \\
\hline$>44.5-47$ & 63 & 62 & 1.13 & $0.77-1.68$ & 0.53 \\
\hline$>47-49.5$ & 51 & 49 & 1.01 & $0.67-1.53$ & 0.96 \\
\hline$>49.5$ & 65 & 61 & 0.83 & $0.56-1.24$ & 0.36 \\
\hline \multicolumn{6}{|l|}{ Navel score } \\
\hline 0 & 163 & 155 & Referent & & \\
\hline$\geq 1$ & 67 & 67 & 1.24 & $0.92-1.67$ & 0.15 \\
\hline \multicolumn{6}{|c|}{ Lymphocyte count $\left(10^{9}\right.$ cells $\left./ \mathrm{L}\right)$} \\
\hline$\leq 3.8$ & 58 & 56 & Referent & & \\
\hline$>3.8-4.8$ & 57 & 57 & 1.14 & $0.77-1.67$ & 0.52 \\
\hline$>4.8-5.8$ & 57 & 54 & 0.96 & $0.65-1.43$ & 0.86 \\
\hline$>5.8$ & 58 & 55 & 0.71 & $0.48-1.06$ & 0.09 \\
\hline
\end{tabular}

${ }^{1}$ Random effect for clustering by the room in which calves were managed, $P=0.02$.

they died before a final weight was recorded $(\mathrm{n}=40)$, had a missing final weight record $(\mathrm{n}=11)$, or had a missing arrival weight record $(\mathrm{n}=2)$. A total of 53 calves were excluded. Mean arrival weight was $47.50 \mathrm{~kg}$ (SD: $4.17 \mathrm{~kg})$, and mean ADG was $0.68 \mathrm{~kg}$ (SD: 0.23 $\mathrm{kg})$.

Two explanatory variables measured at the time of arrival, lymphocyte count and hydration score, were associated with growth over the 77-d study period. In this mixed model, dehydration at the time of arrival (compared with normal hydration status) was associated with a decrease of $0.09 \mathrm{~kg} / \mathrm{d}(95 \% \mathrm{CI}=-0.01$ to $-0.16, P=0.03)$. For every $10^{9}$ cells $/ \mathrm{L}$ increase in lymphocyte count, ADG increased by $0.03 \mathrm{~kg} / \mathrm{d}(95 \%$ $\mathrm{CI}=0.01-0.05, P=0.02)$. Room was statistically significant in the model $(P=0.01$, intraclass correlation

Table 5. Results of the Cox proportional hazard model assessing the significance of the explanatory variables measured from 230 calves at the time of arrival for predicting the hazard of morbidity over the first $21 \mathrm{~d}$ of the study period ${ }^{1}$

\begin{tabular}{|c|c|c|c|c|c|}
\hline Variable & $\begin{array}{c}\text { Calves } \\
\text { (no.) }\end{array}$ & $\begin{array}{c}\text { Morbidity } \\
\text { (no. of calves) }\end{array}$ & $\begin{array}{c}\text { Hazard } \\
\text { ratio }\end{array}$ & $95 \% \mathrm{CI}$ & $P$-value \\
\hline \multicolumn{6}{|c|}{ Rectal temperature $\left({ }^{\circ} \mathrm{C}\right)$} \\
\hline$\leq 39.1$ & 72 & 64 & Referent & & \\
\hline$>39.1-39.3$ & 47 & 42 & 1.27 & $0.84-1.93$ & 0.26 \\
\hline$>39.3-39.6$ & 60 & 52 & 0.91 & $0.63-1.32$ & 0.62 \\
\hline$>39.6$ & 51 & 49 & 1.54 & $1.04-2.27$ & 0.03 \\
\hline \multicolumn{6}{|c|}{ Arrival weight $(\mathrm{kg})$} \\
\hline$\leq 44.5$ & 51 & 49 & Referent & & \\
\hline$>44.5-47$ & 63 & 59 & 1.15 & $0.77-1.73$ & 0.49 \\
\hline$>47-49.5$ & 51 & 45 & 0.99 & $0.65-1.52$ & 0.97 \\
\hline$>49.5$ & 65 & 54 & 0.82 & $0.54-1.23$ & 0.34 \\
\hline \multicolumn{6}{|l|}{ Navel score } \\
\hline 0 & 163 & 144 & Referent & & \\
\hline$\geq 1$ & 67 & 67 & 1.19 & $0.88-1.62$ & 0.27 \\
\hline \multicolumn{6}{|c|}{ Lymphocyte count $\left(10^{9}\right.$ cells $\left./ \mathrm{L}\right)$} \\
\hline$\leq 3.8$ & 58 & 55 & Referent & & \\
\hline$>3.8-4.8$ & 57 & 56 & 1.08 & $0.77-1.67$ & 0.70 \\
\hline$>4.8-5.8$ & 57 & 50 & 0.90 & $0.65-1.43$ & 0.65 \\
\hline$>5.8$ & 58 & 46 & 0.59 & $0.37-0.95$ & 0.03 \\
\hline \multicolumn{6}{|c|}{ Neutrophil count $\left(10^{9}\right.$ cells $\left./ \mathrm{L}\right)$} \\
\hline$\leq 3.6$ & 57 & 54 & Referent & & \\
\hline$>3.6-5.1$ & 58 & 53 & 1.22 & $0.81-1.83$ & 0.34 \\
\hline$>5.1-7.3$ & 58 & 51 & 1.05 & $0.69-1.61$ & 0.82 \\
\hline$>7.3$ & 57 & 49 & 1.08 & $0.66-1.75$ & 0.76 \\
\hline
\end{tabular}

${ }^{1}$ Random effect for clustering by the room in which calves were managed, $P=0.04$. 
Table 6. Results of the Cox proportional hazard model assessing the significance of the explanatory variables measured from 150 calves $72 \mathrm{~h}$ postarrival for predicting the hazard of morbidity over the entire 77 -d study $\operatorname{period}^{1}$

\begin{tabular}{lccccc}
\hline $\begin{array}{l}\text { Lymphocyte count } \\
\left(10^{9} \text { cells/L) }\right.\end{array}$ & $\begin{array}{c}\text { Calves } \\
\text { (no.) }\end{array}$ & $\begin{array}{c}\text { Morbidity } \\
\text { (no. of calves) }\end{array}$ & $\begin{array}{c}\text { Hazard } \\
\text { ratio }\end{array}$ & $95 \%$ CI & $P$-value \\
\hline$\leq 4.6$ & 37 & 37 & Referent & & \\
$>4.6-5.8$ & 37 & 36 & 0.77 & $0.48-1.21$ & 0.26 \\
$>5.8-7.0$ & 39 & 38 & 1.00 & $0.64-1.58$ & 0.99 \\
$>7.0$ & 37 & 35 & 0.56 & $0.35-0.90$ & 0.02 \\
\hline
\end{tabular}

${ }^{1}$ Random effect for clustering by the room in which calves were managed, $P=0.11$.

coefficient $=4.9 \%$ ). No association was identified with blood leukocyte DCC measured $72 \mathrm{~h}$ after arrival and ADG.

\section{DISCUSSION}

This study demonstrates that machine leukocyte DCC measured at the time of arrival are associated with morbidity and growth of calves entering a grain-fed veal facility. Increased lymphocyte counts were found to be associated with decreased hazard of morbidity and higher ADG. When measured $72 \mathrm{~h}$ postarrival, machine leukocyte DCC were associated with morbidity and mortality. Lymphocyte counts between 4.6 and $5.8 \times 10^{9} / \mathrm{L}$ were associated with a decreased hazard of mortality, whereas lymphocyte counts $>5.8 \times 10^{9} / \mathrm{L}$ reduced the hazard of morbidity. Elevated neutrophil counts were associated with an increased hazard of mortality. Dehydration at arrival was associated with lower ADG, and elevated rectal temperatures increased hazard of morbidity. Total protein $\geq 5.2 \mathrm{~g} / \mathrm{dL}$ was associated with a decreased hazard of mortality.

Reports on the length of time before blood cortisol levels and leukocyte counts return to basal levels after prolonged transportation vary from $1 \mathrm{~d}$ to several days (Odore et al., 2004; Bernardini et al., 2012; Yun et al., 2014). The timing of the third sample was selected arbitrarily with the intention to allow for calves to recover from transportation and adjust to their new diet and environment. In this study, few blood leukocyte values measured either upon arrival or $72 \mathrm{~h}$ postarrival were outside of the normal reference interval for neonatal
Holstein calves (Panousis et al., 2018). The difference between measurement time points was, however, statistically significant. This suggests that although the effects of time posttransportation are measurable within leukocyte DCC, they do not elicit a change beyond the normal physiological limits of neonatal Holstein calves as determined by Panousis et al. (2018). Additionally, the relationship between leukocyte counts and future health and growth differed between time points, suggesting that there may be a role for measuring leukocyte counts at both arrival and a time point postarrival. Given that more than one-quarter of the calves arrived with some level of clinically measurable dehydration, it is possible that this accounts for some of the differences detected in leukocyte counts between collection time points (Tornquist and Rigas, 2011). For group management or risk assignment, screening at the time of arrival would be more practical for immediate management decisions. However, for individual calf management or therapeutic decisions, postarrival measures may have more value.

Although most lymphocyte and neutrophil counts were within physiological limits, an association was found between these measurements and the future health and growth in this population of calves. Elevated lymphocyte counts (within the reference interval) at the time of arrival were associated with increased ADG and a decreased hazard of morbidity within the first $21 \mathrm{~d}$ at the facility. When measured $72 \mathrm{~h}$ postarrival, elevated lymphocyte counts were associated with a decreased hazard of morbidity, and a lymphocyte count in the middle of the reference interval $(4.6-5.8 \times$

Table 7. Results of the Cox proportional hazard model assessing the significance of the explanatory variables measured from 150 calves $72 \mathrm{~h}$ postarrival for predicting the hazard of morbidity over the first $21 \mathrm{~d}$ of the study period ${ }^{1}$

\begin{tabular}{lccccc}
\hline $\begin{array}{l}\text { Lymphocyte count } \\
\left(10^{9} \text { cells/L) }\right.\end{array}$ & $\begin{array}{c}\text { Calves } \\
(\text { no. })\end{array}$ & $\begin{array}{c}\text { Morbidity } \\
\text { (no. of calves) }\end{array}$ & $\begin{array}{c}\text { Hazard } \\
\text { ratio }\end{array}$ & 95\% CI & $P$-value \\
\hline$\leq 4.6$ & 37 & 36 & Referent & & \\
$>4.6-5.8$ & 37 & 35 & 0.75 & $0.47-1.20$ & 0.23 \\
$>5.8-7.0$ & 39 & 35 & 0.98 & $0.62-1.55$ & 0.92 \\
$>7.0$ & 37 & 27 & 0.47 & $0.29-0.78$ & $<0.01$ \\
\hline
\end{tabular}

${ }^{1}$ Random effect for clustering by the room in which calves were managed, $P=0.19$. 
$10^{9}$ cells/L) was associated with a decreased hazard of mortality. Because neonatal calves are born with fewer lymphocytes than adults and this number is known to increase with age (Jones and Allison, 2007; Panousis et al., 2018), it is possible that the elevated number of lymphocytes may be an indication of an older age. Older calves may be better prepared to cope with the stress of transportation and comingling, which could explain the association between lymphocyte counts and health. Alternatively, because lymphopenia can be associated with stress, infection, and immune suppression (Jones and Allison, 2007; Roland et al., 2014), a relatively elevated lymphocyte count may be an indicator of resilience to the stress associated with transportation or the absence of challenge to the immune system, such as infection pressure or immune suppression. Elevated neutrophil counts measured $72 \mathrm{~h}$ postarrival were associated with an increased hazard of mortality. Given that calves have elevated neutrophil counts shortly after birth that decrease over the first week of life (Tornquist and Rigas, 2011; Panousis et al., 2018), this finding may be a proxy for younger calves. Another explanation could be that calves with relatively high neutrophil counts are in the process of developing a neutrophilia in response to stress or chronic inflammation due to infection (Tornquist and Rigas, 2011; Roland et al., 2014). If age were known, it might be possible to differentiate between these competing hypotheses.

That hydration status on arrival was a predictor of future growth is consistent with other recent work (Renaud et al., 2018d). Given that more than $90 \%$ of the calves in this study received antibiotic therapy within the first $21 \mathrm{~d}$ at the facility and almost $70 \%$ of those treatments were reported as treatment for diarrhea, loss of fluids via diarrhea may be the cause of the dehydration seen. However, it is also possible that dehydration in this population occurred as a result of prolonged transportation involving fasting or water restriction preventing calves from replacing their maintenance fluid requirements (Knowles et al., 1997, 1999; Marcato et al., 2018). Interestingly, dehydration was not found to be a significant indicator of future mortality as found in previous studies by Renaud et al. (2018a). However, when considering the hypothesized relationship as illustrated in Figure 1, morbidity and mortality are proposed as an intervening variable to $\mathrm{ADG}$.

Elevated rectal temperature $\left(>39.6^{\circ} \mathrm{C}\right)$ was associated with increased morbidity over the entire study period as well as in the first $21 \mathrm{~d}$ at the facility. This result differs from previous reports that did not find rectal temperature to be predictive of mortality (Marcato et al., 2018; Renaud et al., 2018a). Rectal temperature can be affected by stressors, such as transportation and handling (Burdick et al., 2010; Bernardini et al., 2012;
Marcato et al., 2018). The association found in this study may reflect clinical or subclinical disease at the time of measurement. This is suggested because more than $34 \%$ of calves received antibiotic therapy within the first $3 \mathrm{~d}$ at the facility, and the facility observed very high levels of morbidity and mortality over the entire production period.

Serum total protein values $<5.2 \mathrm{~g} / \mathrm{dL}$ were determined to be a predictor of mortality. It was unsurprising given that total protein values $<5.2 \mathrm{~g} / \mathrm{dL}$ are associated with a failure of passive transfer, as this has been found to be associated with increased morbidity and mortality in veal calves (Marcato et al., 2018; Renaud et al., 2018b). Although an association between total protein and morbidity was not observed in this study, it is possible that the association was obscured by the high level of morbidity reported as the result of a disease outbreak.

Inter- and intraobserver agreement for health measures was assessed using percent agreement as opposed to Cohen's kappa, which may overestimate the level of agreement and does not account for agreement due to chance (McHugh, 2012). This limitation was due to the small sample size of calves measured for this purpose. However, laminated reference materials with images and definitions of all health scores, as well as a dowel for scoring navel size, were available to both observers at all times during data collection. Additionally, both observers performed health measurement scoring on more than 500 calves together during data collection in a separate trial. Agreement between observers was greater than $90 \%$ for all health measurements with the exception of hydration, which had $75 \%$ agreement.

The high levels of mortality experienced at the facility over the study period exceed the 4 to $8 \%$ mortality risk reported in the literature (Pardon et al., 2012; Winder et al., 2016; Scott et al., 2019). Historically, mortality rates at this facility have been reported at $7.5 \%$ and treatment rates at $87 \%$ (Scott et al., 2019). This increase in morbidity and mortality was the result of an outbreak of Salmonella enterica serotype Dublin, which is associated with high levels of mortality and the presence of calves that are either clinically affected or in a carrier state (Mohler et al., 2009; Holschbach and Peek, 2018). It is possible that this outbreak could affect the external validity of study findings as the population studied may not be representative of the average grain-fed veal herd; however, there has been an increase in prevalence of this pathogen in groupfed dairy calves in recent years (Holschbach and Peek, 2018). Additionally, the high levels of mortality lead to the exclusion of a large number of calves that died before a second weight was recorded for the purpose of ADG calculations. Given that disease can affect calf 
growth (Donovan et al., 1998), it is possible that this resulted in survival bias in models of ADG favoring calves with higher ADG.

In this study, treatment was used as a proxy for morbidity. The facility staff were experienced and used respiratory and fecal health scores (McGuirk, 2008; McGuirk and Peek, 2014) in their treatment protocol, lending some confidence to this definition for morbidity. However, since this is not a direct measure of morbidity, it could have been subject to bias if staff were prone to over- or undertreating disease cases. This highlights the importance of clearly reporting the definition of outcomes and how it was measured because there can be a large amount of variability in treatment protocols.

\section{CONCLUSIONS}

This study demonstrates that machine leukocyte DCC measured at the time of arrival and $72 \mathrm{~h}$ after arrival were indicators of future morbidity, mortality, and growth in calves arriving to calf rearing facilities. Further work could help determine the effects of time posttransportation on blood leukocyte measurements to further refine the most useful time after arrival to measure these values. Future studies focused on refining rapid risk assessment protocols as well as determining the best strategy for managing calves at either the individual or group level will help reduce antimicrobial use at the time of arrival by guiding selective antimicrobial therapy efforts.

\section{ACKNOWLEDGMENTS}

The authors of this study thank the research assistant involved in data collection and the farm staff for their cooperation. Funding for this study was provided by the Ontario Ministry of Agriculture, Food and Rural Affairs (OMAFRA, Guelph, ON, Canada), the Veal Farmers of Ontario (Guelph, ON, Canada), the Ontario Veterinary College (University of Guelph, ON, Canada), Mapleview Agri Ltd. (Palmerston, ON, Canada), and Advanced Animal Diagnostics (Morrisville, NC). The authors have not stated any conflicts of interest.

\section{REFERENCES}

Bernardini, D., G. Gerardi, A. Peli, L. Nanni Costa, M. Amadori, and S. Segato. 2012. The effects of different environmental conditions on thermoregulation and clinical and hematological variables in long-distance road-transported calves. J. Anim. Sci. 90:1183-1191. https://doi.org/10.2527/jas.2011-4113.

Buczinski, S., E. Gicquel, G. Fecteau, Y. Takwoingi, M. Chigerwe, and J. M. Vandeweerd. 2018. Systematic review and meta-analysis of diagnostic accuracy of serum refractometry and Brix refractometry for the diagnosis of inadequate transfer of passive immunity in calves. J. Vet. Intern. Med. 32:474-483. https://doi.org/10.1111/ jvim.14893.

Burdick, N., J. Carroll, L. Hulbert, J. Dailey, S. Willard, R. Vann, T. Welsh Jr., and R. Randel. 2010. Relationships between temperament and transportation with rectal temperature and serum concentrations of cortisol and epinephrine in bulls. Livest. Sci. 129:166-172. https://doi.org/10.1016/j.livsci.2010.01.020.

Calloway, C. D., J. W. Tyler, R. K. Tessman, D. Hostetler, and J. Holle. 2002. Comparison of refractometers and test endpoints in the measurement of serum protein concentration to assess passive transfer status in calves. J. Am. Vet. Med. Assoc. 221:1605-1608. https://doi.org/10.2460/javma.2002.221.1605.

Donovan, G. A., I. R. Dohoo, D. M. Montgomery, and F. L. Bennett. 1998. Calf and disease factors affecting growth in female Holstein calves in Florida, USA. Prev. Vet. Med. 33:1-10. https://doi.org/ 10.1016/S0167-5877(97)00059-7.

EMA Committee for Medicinal Products for Veterinary Use, EFSA Panel on Biological Hazards, Murphy, D., A. Ricci, Z. Auce, G.J. Beechinor, H. Bergendahl, R. Breathnach, J. Bureš, J. Silva, J. Hederová, P. Hekman, C. Ibrahim, E. Kozhuharov, G. Kulcsár, E. Persson, J.M. Lenhardsson, P. Mačiulskis, I. Malemis, L. Markus-Cizelj, A. Michaelidou-Patsia, M. Nevalainen, P. Pasquali, J. Rouby, J. Schefferlie, W. Schlumbohm, M. Schmit, S. Spiteri, S. Srčič, L. Taban, T. Tiirats, B. Urbain, E. Vestergaard, A. Wachnik-Święcicka, J. Weeks, B. Zemann, A. Allende, D. Bolton, M. Chemaly, P. Escamez, R. Girones, L. Herman, K. Koutsoumanis, R. Lindqvist, B. Nørrung, L. Robertson, G. Ru, M. Sanaa, M. Simmons, P. Skandamis, E. Snary, N. Speybroeck, B. Kuile, H Wahlström, K. Baptiste, B. Catry, P. Cocconcelli, R. Davies, C. Ducrot, C. Friis, G. Jungersen, S. More, C. Madero, P. Sanders, M. Bos, Z. Kunsagi, J. Edo, R. Brozzi, D. Candiani, B. Guerra, E. Liebana, P. Stella, J. Threlfall, and H. Jukes. 2017. EMA and EFSA Joint Scientific Opinion on measures to reduce the need to use antimicrobial agents in animal husbandry in the European Union, and the resulting impacts on food safety (RONAFA). EFSA J. 15:e04666. https://doi.org/10.2903/j.efsa.2017.4666.

Godden, S. 2008. Colostrum management for dairy calves. Vet. Clin. North Am. Food Anim. Pract. 24:19-39. https://doi.org/10.1016/ j.cvfa.2007.10.005.

Hahn, G. J., and W. Q. Meeker. 2011. Statistical Intervals: A Guide for Practitioners. Wiley, Hoboken, NJ.

Holschbach, C. L., and S. F. Peek. 2018. Salmonella in dairy cattle. Vet. Clin. North Am. Food Anim. Pract. 34:133-154. https://doi .org/10.1016/j.cvfa.2017.10.005.

Jones, M. L., and R. W. Allison. 2007. Evaluation of the ruminant complete blood cell count. Vet. Clin. North Am. Food Anim. Pract. 23:377-402. https://doi.org/10.1016/j.cvfa.2007.07.002.

Knowles, T. G., P. Warriss, S. Brown, and J. Edwards. 1999. Effects on cattle of transportation by road for up to 31 hours. Vet. Rec. 145:575-582. https://doi.org/10.1136/vr.145.20.575.

Knowles, T. G, P. Warriss, S. Brown, J. Edwards, P. Watkins, and A. Phillips. 1997. Effects on calves less than one month old of feeding or not feeding them during road transport of up to 24 hours. Vet. Rec. 140:116-124. https://doi.org/10.1136/vr.140.5.116.

Kull, J. A., P. D. Krawczel, and G. M. Pighetti. 2018. Short communication: Evaluation of an automated method for assessing white blood cell concentrations in Holstein dairy cows. Vet. Immunol. Immunopathol. 197:21-23. https://doi.org/10.1016/j.vetimm.2018 .01 .002 .

Marcato, F., H. van den Brand, B. Kemp, and K. van Reenen. 2018. Evaluating potential biomarkers of health and performance in veal calves. Front. Vet. Sci. 5:133. https://doi.org/10.3389/fvets.2018 .00133

McGuirk, S. M. 2008. Disease management of dairy calves and heifers. Vet. Clin. North Am. Food Anim. Pract. 24:139-153. https://doi .org/10.1016/j.cvfa.2007.10.003.

McGuirk, S. M., and S. F. Peek. 2014. Timely diagnosis of dairy calf respiratory disease using a standardized scoring system. Anim. Health Res. Rev. 15:145-147. https://doi.org/10.1017/ S1466252314000267. 
McHugh, M. L. 2012. Interrater reliability: The kappa statistic. Biochem. Med. (Zagreb) 22:276-282. https://doi.org/10.11613/BM .2012.031.

Mohler, V. L., M. M. Izzo, and J. K. House. 2009. Salmonella in calves. Vet. Clin. North Am. Food Anim. Pract. 25:37-54. https://doi .org/10.1016/j.cvfa.2008.10.009.

Mohri, M., K. Sharifi, and S. Eidi. 2007. Hematology and serum biochemistry of Holstein dairy calves: Age related changes and comparison with blood composition in adults. Res. Vet. Sci. 83:30-39. https://doi.org/10.1016/j.rvsc.2006.10.017.

Odore, R., A. D'Angelo, P. Badino, C. Bellino, S. Pagliasso, and G. Re. 2004. Road transportation affects blood hormone levels and lymphocyte glucocorticoid and $\beta$-adrenergic receptor concentrations in calves. Vet. J. 168:297-303. https://doi.org/10.1016/j.tvjl 2003.09.008

Panousis, N., N. Siachos, G. Kitkas, E. Kalaitzakis, M. Kritsepi-Konstantinou, and G. E. Valergakis. 2018. Hematology reference intervals for neonatal Holstein calves. Res. Vet. Sci. 118:26. https://doi .org/10.1016/j.rvsc.2018.01.002.

Pardon, B., K. De Bleecker, M. Hostens, J. Callens, J. Dewulf, and P. Deprez. 2012. Longitudinal study on morbidity and mortality in white veal calves in Belgium. BMC Vet. Res. 8:26. https://doi.org/ 10.1186/1746-6148-8-26.

Renaud, D. L., T. F. Duffield, S. J. LeBlanc, S. Ferguson, D. B. Haley, and D. F. Kelton. 2018a. Risk factors associated with mortality at a milk-fed veal calf facility: A prospective cohort study. J. Dairy Sci. 101:2659-2668. https://doi.org/10.3168/jds.2017-13581.

Renaud, D. L., T. F. Duffield, S. J. LeBlanc, D. B. Haley, and D. F. Kelton. 2018b. Clinical and metabolic indicators associated with early mortality at a milk-fed veal facility: A prospective case-control study. J. Dairy Sci. 101:2669-2678. https://doi.org/10.3168/ jds.2017-14042.

Renaud, D. L., D. F. Kelton, S. J. LeBlanc, D. B. Haley, and T. F. Duffield. 2018c. Calf management risk factors on dairy farms associated with male calf mortality on veal farms. J. Dairy Sci. 101:1785-1794. https://doi.org/10.3168/jds.2017-13578.

Renaud, D. L., M. W. Overton, D. F. Kelton, S. J. LeBlanc, K. C. Dhuyvetter, and T. F. Duffield. 2018d. Effect of health status evaluated at arrival on growth in milk-fed veal calves: A prospective single cohort study. J. Dairy Sci. 101:10383-10390. https://doi .org/10.3168/jds.2018-14960.
Roland, L., M. Drillich, and M. Iwersen. 2014. Hematology as a diagnostic tool in bovine medicine. J. Vet. Diagn. Invest. 26:592-598. https://doi.org/10.1177/1040638714546490.

Santman-Berends, I. M. G. A., A. J. G. de Bont-Smolenaars, L. Roos, A. G. J. Velthuis, and G. van Schaik. 2018. Using routinely collected data to evaluate risk factors for mortality of veal calves. Prev. Vet. Med. 157:86-93. https://doi.org/10.1016/j.prevetmed .2018.05.013.

Scott, K., D. F. Kelton, T. F. Duffield, and D. L. Renaud. 2019. Risk factors identified on arrival associated with morbidity and mortality at a grain-fed veal facility: A prospective, single-cohort study. J. Dairy Sci. 102:9224-9235. https://doi.org/10.3168/jds.2019-16829.

Speksnijder, D. C., and J. A. Wagenaar. 2018. Reducing antimicrobial use in farm animals: How to support behavioral change of veterinarians and farmers. Anim. Front. 8:4-9. https://doi.org/10.1093/ af/vfy006.

Tornquist, S. J., and J. Rigas. 2011. Schalm's veterinary hematology. Vet. Clin. Pathol. 40:307-313. https://doi.org/10.1111/j.1939 $-165 x .2011 .00324 . x$

von Konigslow, T. E., D. L. Renaud, T. F. Duffield, V. Higginson, and D. F. Kelton. 2019. Validation of an automated cell counter to determine leukocyte differential counts in neonatal Holstein calves. J. Dairy Sci. 102:7445-7452. https://doi.org/10.3168/jds.2019-16370.

Winder, C. B., D. F. Kelton, and T. F. Duffield. 2016. Mortality risk factors for calves entering a multi-location white veal farm in Ontario, Canada. J. Dairy Sci. 99:10174-10181. https://doi.org/10 $.3168 /$ jds.2016-11345.

Yun, C.-H., P. Wynn, and J. K. Ha. 2014. Stress, acute phase proteins and immune modulation in calves. Anim. Prod. Sci. 54:1561-1568. https://doi.org/10.1071/AN14441.

\section{ORCIDS}

T. E. von Konigslow (1) https://orcid.org/0000-0002-4005-4359

D. L. Renaud (1) https://orcid.org/0000-0002-3439-3987

T. F. Duffield ๑ https://orcid.org/0000-0001-6035-4669

C. B. Winder (ㄴ) https://orcid.org/0000-0002-7314-3657

D. F. Kelton (ํ) https://orcid.org/0000-0001-9606-7602 